\title{
Micro-Environmental Changes in Wounds are Significantly Influenced by Intermittent Pneumatic Impulse Compression (IIC)
}

\author{
Thomas Eberlein and Michael Schmitz* \\ Dermatologist/Venerologist - Allergist, Clinical expert for Certification of QM systems, Authorised expert, TÜV Austria; WCC \\ Wound Competence Centre, Linz, Austria
}

*Corresponding author: Thomas Eberlein, Dermatologist/Venerologist - Allergist, Clinical expert for Certification of QM systems,

Authorised expert, TÜV Austria; WCC Wound Competence Centre, Linz, Austria

\section{ARTICLE INFO}

Received: 幽 February 17, 2020

Published: 蔧 February 25, 2020

\section{ABSTRACT}

Citation: Thomas Eberlein, Michael Schmitz. Micro-Environmental Changes in Wounds are Significantly Influenced by Intermittent Pneumatic Impulse Compression (IIC). Biomed J Sci \& Tech Res 26(1)-2020. BJSTR. MS.ID.004282.

\section{Short Communication}

Wound $\mathrm{pH}$ remains in the focus of scientific considerations for the diagnosis and treatment of chronic wounds as emphasized in recent studies [1-7]. Supported by abundant evidence, it may be taken for granted that a rapid acute wound healing occurs with low, acidic $\mathrm{pH}$ values at starting points below a $\mathrm{pH}$ value of 3 . This difference in the wound environmental $\mathrm{pH}$ value in acute and chronic wounds has been shown to be relative to differences in the character of exudate which affects $\mathrm{pH}$ value $[2,3,5,6]$. Progress in treatment of these wounds is frequently accompanied by reduction in $\mathrm{pH}$. Restarting the reparative processes is associated to acidic $\mathrm{pH}$ levels (e.g., 6.5) [6]. Due to the availability of commercial $\mathrm{pH}$ and temperature measurement devices, a real-time bedside monitoring is now feasible without prior calibration, directly inside the wound without extraction of exudate and in coincidence of $\mathrm{pH}$ and temperature measurement in approximately 20-30 seconds. Topic as well as systemic factors can influence the microenvironment inside wounds. There is only a limited availability of data about the relationship between microcirculation and wound $\mathrm{pH}$ [7]. Hence, we have collected the/our first own data about the influence of intermittent pneumatic compression (IPC) using impulse technology (intermittent impulse compression, IIC) on wound temperature and $\mathrm{pH}$ in venous leg ulcerations (VLU).

\section{Materials and Methods}

Parallel to a running study, we started the measurement of $\mathrm{pH}$ and temperature inside VLU with $(\mathrm{n}=11)$ and without $(\mathrm{n}=5)$ using IIC (Vadoplex, Oped, Valley, Germany) over a time of two hours with continuous compression application. Patients were immobilized for this period with moderate elevation of the legs and application of intermittent impulse compression using foot cuffs ( $\mathrm{f}=3 / \mathrm{min}$; pressure application time [single impulse] tAppl= $1 \mathrm{sec}$ ) for the treatment group and without additional application of compression for control group. Measurement has taken place at the start (t0), after $30 \mathrm{~min}(\mathrm{t} 1), 60 \mathrm{~min}(\mathrm{t} 2)$ and finally after 120 min ( $\mathrm{t} 3$ ) by using the/a wound $\mathrm{pH}$-meter (pH-meter TR 26, NAWA Technology, Nuremberg, Germany). In the meantime, wounds were covered by application of a temporary gauze dressing wetted by a neutral, non-buffered solution ( $\mathrm{NaCl} 0.9 \%)$.

\section{Results}

We measured $59 \mathrm{pH}$ values and wound temperatures in 11 patients with chronic wounds of venous origin, detecting $\mathrm{pH}$ values from 6.1 to 8.2 and temperature values between $27.2^{\circ} \mathrm{C}$ and $33.4^{\circ} \mathrm{C}$ at t0. Over a period of 120 minutes, individual $\mathrm{pH}$-values varied up to 1.3 units and temperature values up to 2,0 degrees. In the IIC group, the mean $\mathrm{pH}$ value changed from 7.55 (7.2-8.2) at baseline (t0) to 6.75 (6.3-7.2) after a treatment period of 120 minutes (T-Test $\mathrm{p}=0,000)$. Wound temperature changed from $29.73^{\circ} \mathrm{C}(28.0$ $31.6)$ at baseline to $30.07^{\circ} \mathrm{C}\left(27.7^{\circ} \mathrm{C}-31.0^{\circ} \mathrm{C}\right)$ after 120 minutes, respectively (Student's T-test, $\mathrm{p}=0,212$ ). In the control group, the mean $\mathrm{pH}$ value changed from 7.62 (7.4-7.8) at baseline to 7.63 (7.48.0) at time point $t 3$ (T-test $p=0,789$ ). Wound temperature changed 
from $30.72^{\circ} \mathrm{C}(28.3-33.1)$ at baseline to $31.30^{\circ} \mathrm{C}\left(29.9^{\circ} \mathrm{C}-33.0^{\circ} \mathrm{C}\right)$ after 120 minutes (T-test $\mathrm{p}=0,389$ ). Provided that $\mathrm{pH}$ value of 6.5 supports the restarting of reparative processes without too much uncertainty, the mean $\mathrm{pH}$ value of the IPC-group after 120 minutes reaches the target $\mathrm{pH}$-level more distinctively (unpaired T-test, test-level $6.5, \mathrm{p}=0.089$ ) than the mean $\mathrm{pH}$ value of the controlgroup (unpaired T-test, test-level $6.5 \mathrm{p}=0.004$ ). The results are demonstrated in Figure 1.

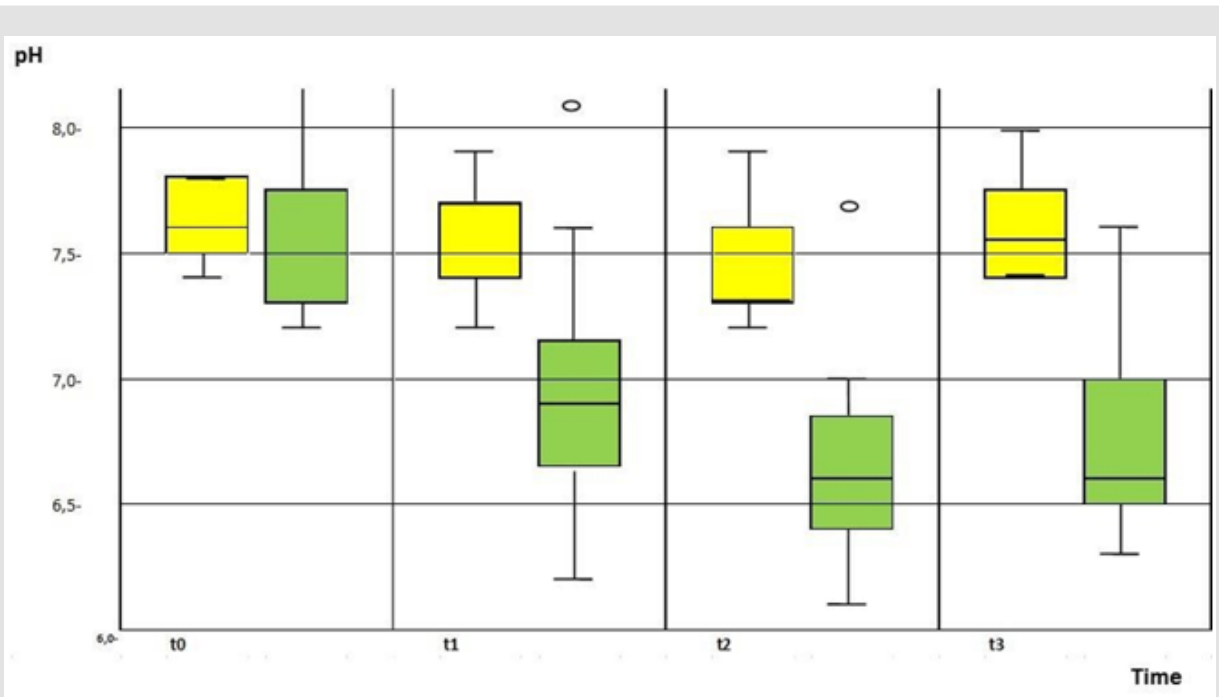

Figure 1: pH over time with (green) and without (yellow) IIC over time.

\section{Discussion}

Our data shows the influence of the application of IIC compared to no compression in patients suffering from VLU. While no significant changing in wound temperature has been observed, wound $\mathrm{pH}$ was strongly influenced by the application of IIC $(p=0,000)$ and compared to control group. Without the application of compression, there is a significant difference between real wound $\mathrm{pH}$ and target $\mathrm{pH}$ value (6.5). Meanwhile the treatment group shows an impressive approximation to target $\mathrm{pH}$ value. These results support the suggestion that the normalization of microcirculation caused by application of IIC can modify the microenvironmental conditions inside the wound. Following the existing and established evidence that wound healing is directly linked to acidic $\mathrm{pH}$ levels, our results hypothesize a direct connection between IIC and restarting of reparative processes in the healing of VLU.

\section{Declaration of Interest}

The authors declare no conflict of interest.

\section{ISSN: 2574-1241}

DOI: $10.26717 /$ BJSTR.2020.26.004282

Thomas Eberlein. Biomed J Sci \& Tech Res

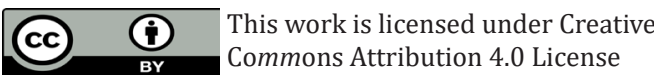

Submission Link: https://biomedres.us/submit-manuscript.php

\section{References}

1. Mayuzumi J, Kikuchi N, Arai S (1980) Seasonal variations in skin temperature, skin $\mathrm{pH}$, eporative water loss and skin surface lipid values on human skin. Chem Pharm Bull 28: 387-392.

2. Dissemond J, Witthoff M, Brauns TC, Haberer D, Goos M (2003) Untersuchungen zum pH-Wert des Milieus chronischer Wunden im Rahmen einer modernen Wundtherapie.Hautarzt 54: 959-965.

3. Glibbery A, Mani R (1992) pH in leg ulcers. J Microcirc Clin Exp 11: 109.

4. Romanelli M (2003) Objective assessment during wound bed preparation. In: New concepts in wound bed preparation Falanga V [Edn.], Springer Verlag Berlin, Heidelberg, New York, 1(28): 23-34.

5. Gethin G (2007) The significance of surface $\mathrm{pH}$ in chronic wounds. Wounds, UK. 3(3): 52-56.

6. Schneider LA, Körber A, Grabbe S, Dissemond J (2007) Influence of pH on wound-healing: A new perspective for wound-therapy. Arch Derm Research 298(9): 413-420.

7. Percival SL, Mc Carty S, Hunt JA, Woods EJ (2014) The effects of pH on wound healing, biofilms, and antimicrobial efficacy. Wound Repair Regen 22(2):174-186.

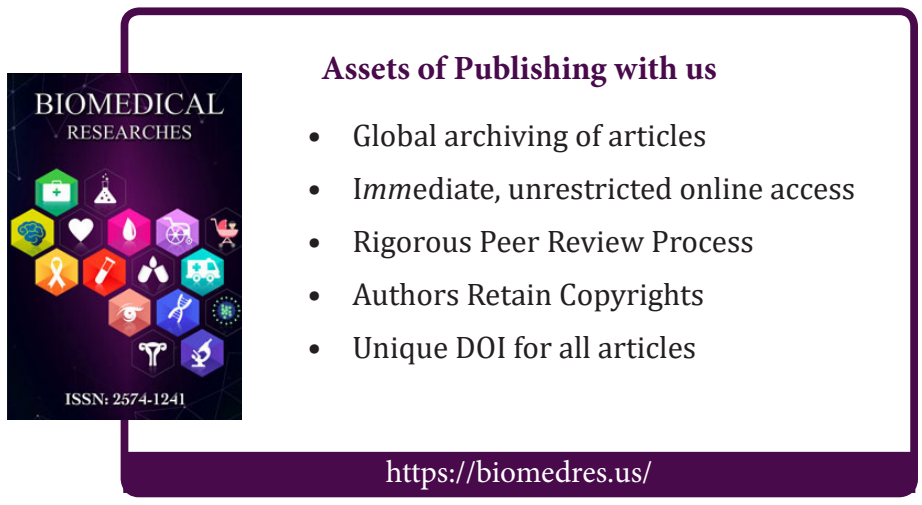

Copyright@ Thomas Eberlein | Biomed J Sci \& Tech Res | BJSTR. MS.ID.004282. 